and from a plate taken with the $I$ camera (Cambridge, 8-in. aperture). The first was on Jan. 0.9908 and the other on Jan. 29.00698, and from these and an observation on January 19 they have computed the following orbit :

$\left.\begin{array}{lcr}T & 1941 & \text { Jan. } 20 \cdot 633 \text { U.T. } \\ \omega & 132^{\circ} & 35 \cdot 9^{\prime} \\ \Omega & 329 & 2.9 \\ i & 26 & 36.5\end{array}\right\} 1941.0$

Comet Encke. Harvard Card 561 announces that Van Biesbroeck, Yerkes Observatory, reports the discovery of this comet on Jan. 19.033. It is described as diffuse with a nucleus, the magnitude being 17 . In the "Handbook of the British Astronomical Association, 1941", the late Dr. A. C. D. Crommelin gave the elements and an ephemeris, and the comet is very close to the predicted position.

Comet Paraskevopoulos (1941 c). This comet was discovered by Dr. John S. Paraskevopoulos, of the Boyden Station, Bloemfontein, on January 23, and also by Dr. R. Grandon and others. Its magnitude was stated to be 3.5 and its tail was $5^{\circ}$ in length. An orbit computed by Wood and Jackson, and cabled by Dr. John Jackson, Cape of Good Hope, is given below, and also an ephemeris:

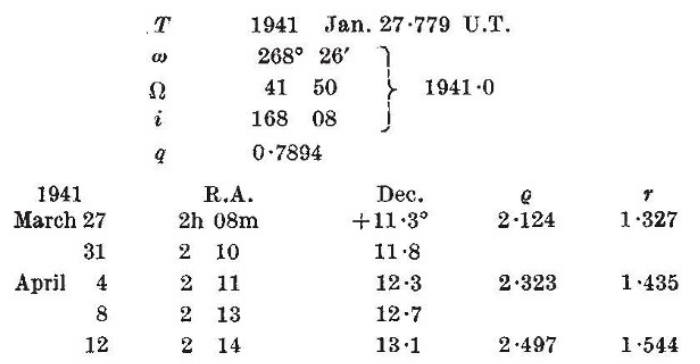

Comet Okabayasi-Honda $(1940 e)$. This comet was discovered at Tokyo on October 4 and was described as being of magnitude 11 and possessing a nucleus. The elements of an orbit and also an ephemeris, computed by Miss E. L. Scott and Mr. H. A. Panofsky, of the University of California, are given below :

\begin{tabular}{|c|c|c|c|c|c|c|c|}
\hline & $T$ & 1940 & Aug & g. 15 & 5.8440 & U.T. & \\
\hline & $\omega$ & $329^{\circ}$ & $50^{\prime}$ & $16^{\prime \prime}$ & ) & & \\
\hline & $\Omega$ & 127 & 15 & 15 & ' & $1940 \cdot 0$ & \\
\hline & $i$ & 133 & 07 & 30 & j & & \\
\hline & $q$ & 1.06 & 372 & & & & \\
\hline & $e$ & 1.00 & 345 & & & & \\
\hline 1941 & & .A. & & Dec & & $\varrho$ & $r$ \\
\hline March 27 & $1 \mathrm{~h}$ & $10 \cdot 6 \mathrm{~m}$ & & $48^{\circ}$ & $52^{\prime}$ & $3 \cdot 903$ & $3 \cdot 314$ \\
\hline April 4 & 1 & $17 \cdot 3$ & & 49 & 03 & & \\
\hline 12 & 1 & $23 \cdot 8$ & & 49 & 22 & $4 \cdot 185$ & $3 \cdot 490$ \\
\hline 20 & 1 & $30 \cdot 2$ & & 49 & 49 & & \\
\hline 28 & 1 & $36 \cdot 0$ & & 50 & 22 & $4 \cdot 410$ & $3 \cdot 663$ \\
\hline
\end{tabular}

\section{The Night Sky in April}

The moon is full on April 11 at 21h. and new on April 26 at 13h. U.T. A naked-eye star, o Leonis (mag. 3.8) is occulted on April 7, the disappearance, as seen from Greenwich, taking place at $21 \mathrm{~h} .43 \cdot 5 \mathrm{~m}$. at position angle $58^{\circ}$ from the north point of the moon's image. Jupiter and its companion, Saturn, are planets of the evening sky. Both will soon be too close to the sun for observation, but they will re-emerge as morning stars towards the end of June. Mars continues as a morning star, and is $5^{\circ}$ above the eastern horizon about $3 \mathrm{~h}$. $30 \mathrm{~m}$. U.T. in midApril. The distant planet, Neptune, is not far from $\beta$ Virginis and comes to the southern meridian shortly after 22h. U.T. in mid-April (add $1 \mathrm{~h}$. to convert to Summer Time). This planet, seen as a star of magnitude 8 , requires for its detection some telescopic aid and a section of a star map for guidance such as is given in the "Handbook of the British Astronomical Association, 1941", p. 9. In the same constellation is one of the best-known binary stars, $\gamma$ Virginis. The components are of nearly equal magnitude $(3 \cdot 6$ and $3 \cdot 7$ respectively) and their present separation is 5 : ; the period is about 180 years. The Lyrid meteors are most frequent about April 20, their radiant point being near 104 Herculis, that is, south. preceding the bright star, Vega.

\section{Announcements}

DR. F. C. HAPPOLD, lecturer in biochemistry in the University of Leeds, has been elected to the recently instituted readership in biochemistry.

THE Herbert Jackson Prize of the London; Midland and Scottish Railway for 1940 has been awarded to Mr. S. C. Britton, of the Metallurgical Department (Engineering Section), Derby, for his paper entitled "The Corrosion of Copper and some Copper Alloys in Atmospheres highly polluted with Coal Smoke".

THE Chemical Society will attain its centenary on March 30, and will hold the hundredth annual general meeting at Burlington House on Thursday, April 3. The business portion of the meeting will be at 12 noon when the election of Prof. J. C. Philip as president, and of those fellows nominated to fill vacancies among elected ordinary members of Council will be announced. At 2.45 Sir Robert Robinson, the retiring president, will deliver his presidential address entitled "The Mechanism of the Benzidine Rearrangement and some Related Topics". Arrangements for the celebration of the centenary of the Society have been postponed until after the War.

Ar the annual general meeting of the Royal Astronomical Society held on March 14, the following officers were elected for the ensuing year : President, Prof. S. Chapman; Vice-Presidents, Prof. David Brunt, Sir James Jeans, the Rev. T. E. R. Phillips, Prof. H. C. Plummer; Treasurer, Mr. J. H. Reynolds; Secretaries, Mr. D. H. Sadler, Dr. A. D. Thackeray ; Foreign Secretary, Sir Arthur Eddington.

The publication "Rubber and its many Uses", by H. McKay, in "The Empire at Work" series (Oxford University Press, 1940) deals, in 76 pages, and in very simple language with the production of rubber in the plantation and the way in which it is manufactured into various articles such as sponges, tubes, tyres, tennis and golf balls, and hard rubber. The whole is well illustrated. The price is $10 d$. 